\title{
ADSORPTION ISOTHERM OF METHYLENE BLUE DYE ON GROUNDNUT SHELL AND SORGHUM HUSK
}

\author{
KYAUTA SUNDAY, ERUGO IMMACULATE AMARACHI, \\ sundaykya@gmail.com
}

Chemical engineering Department, Abubakar Tafawa Balewa university, Bauchi, Nigeria.

\begin{abstract}
Dye removal using low cost adsorbent is a suitable method for textile wastewater treatment. The aim of this research work is application of groundnut shell and sorghum husk in powdered form as low cost adsorbent for methylene blue and Congo red dye removal from water at laboratory scale. Batch studies were carried out to determine the adsorption equilibrium of methylene blue and Congo red dye on the two different adsorbent and also to verify the reported data using Langmuir, Freundlich and Temkin isotherm. The study revealed that for the adsorption of methylene blue on sorghum husk, Langmuir Isotherm fitted well the experimental data with $R^{2}$ value of 0.9710 , while for the adsorption of methylene blue on groundnut shell. The Temkin binding energy $\left(b_{T}\right)$ are positive for all the experiment, indicating that the process is endothermic. The present work will help to carry out studies in packed column and later scale it up for industrial application.
\end{abstract}

\section{ABBREVIATION}

$\mathrm{MB}=$ methylene blue dye

$\mathrm{GS}$ = groundnut shell

$\mathrm{SH}=$ sorghum husk 
$\mathrm{UV}=$ ultraviolent spectrophotometer

\section{Background}

The released voluminous amount of toxic Substances in to the water system has affected the human beings as well as aquatic animals. Dyes are used extensively in various industries such as textiles, rubber, plastics, printing, leather, cosmetics, etc., and also in production of colored products. Dyes affect the penetration of sunlight into the water bodies and thus interfere with the growth of bacteria and hinder photosynthesis in aquatic plant. It poses a serious threat to mankind and water quality, thereby is a matter of vital concern. It causes acute and chronic effects on exposure to human skins such as allergic, dermatitis, skin irritation, cancer, mutation etc. It is very difficult to separate dye from water by using Using conventional techniques ( K. Upadihyay, 2019). Among the various treatment methods, adsorption process, chemical coagulation flocculation degradation process etc. have been explored to remediate these dyes in the waste water (S. Khattri, 2016). Among the various techniques available for its remediation adsorption technique has been proved to be most effective process. Adsorption is preferred over other processes due to possible regeneration and recovery of the sorbet. 
Adsorption is an unit operation process which refers to attachment of molecules of liquid or gas on the surface solid substance. It is based on the fact that some solids preferentially adsorb other solute from the solution onto their surfaces. Dyes are particularly removed using various adsorbents. Many such adsorbents have been explored for its removal. However, in this research work we considered adsorption process using groundnut shell and sorghum husk

\subsection{PROBLEM STATEMENT}

The world is becoming more industrialized therefore the amount of toxic material (e. $g$ dye) released in to the environment is becoming high, some agricultural by-product can be used for water purification so as to comply with the environmental regulation.

\subsection{AIM AND OBJECTIVE}

The aim of the research work is to study the adsorption Isotherm for methylene blue dye on groundnut shell and sorghum husk.

\section{The objectives of the research work are:}

1. To determine the adsorption isotherm that best fits the batch adsorption data.

2. To determine values of Langmuir, freunlish and Temkin constants which defined the adsorption process.

\subsection{SCOPE.}

The research is limited to the adsorption of methylene blue dye using groundnut shell and sorghum husk, and the Isotherm model used are Langmuir, Freundlich and Temkin Isotherm. 


\subsection{Justification;}

1. Massive amount of groundnut shell and sorghum husk are readily available to be used as potential material for adsorption instead of being disposed and causing environmental pollution.

\section{LITERATURE REVIEW}

\subsection{Adsorption Isotherms}

Isotherms give an equilibrium relationship between the amounts of adsorbate adsorbed on the adsorbent surface and its concentration in the solution at a constant temperature. Numerous adsorption models are available in the literature to fit the experimental adsorption data. In this study, the data were fitted using Langmuir Freundlich and Temkin models. Each of the these models makes use of a parameter $\mathrm{q}_{\mathrm{e}}$ (i.e. adsorption capacity per unit mass of the adsorbent at equilibrium) in $\mathrm{mg} / \mathrm{g}$

$q_{e}=\left(\mathrm{C}_{0}-\mathrm{C}_{\mathrm{e}}\right) \mathrm{V} / \mathrm{X}$

$\mathrm{C}_{0}=$ Initial concentration of solution $(\mathrm{mg} / \mathrm{l})$

$\mathrm{C}_{\mathrm{e}}=$ Equilibrium concentration of solution in $(\mathrm{mg} / \mathrm{l})$

$V=$ volume of the solution used

$X=$ mass of the adsorbent used

\subsubsection{Langmuir Isotherm Model}

Langmuir Isotherm model assumed monolayer adsorption (the adsorbed layer is one molecule in thickness) with adsorption can only occur finite (fixed) number of definite localized sides that are identical and equivalent with no lateral interaction and steric hindrances between the adsorbed molecule even on adjacent sites, in other words, sorption sorption occur in a specific homogeneous site within the adsorbent site of the sorbents are identical and energetically equivalent. In its deviation, Langmuir 
isotherm refers to the homogeneous sorption which each molecules possess a contact enthalpies and sorption activation energy (all side possess the equal affinity for the adsorbate). With no transmission of adsorbed in place of surface. Graphically it is characterized by a place an equilibrium saturation point where one molecule occupy a site, no further adsorption can take place. The Langmuir isotherms is widely used and has found a successful application in many real sorption process. Moreover, Langmuir theory has related rapid decrease of the intermolecular attractive forces to the rise of distance (Dolphen et al,. 2016).

The linear form of Langmuir expression:

$\frac{C_{e}}{q_{e}}=\frac{1}{q_{o} b}+\frac{C_{e}}{q_{o}}$

Where

$C_{e}$ is the equilibrium concentration of dye solution $(\mathrm{mg} / \mathrm{L})$,

$q_{e}$ is the equilibrium capacity of dye on the adsorbent $(\mathrm{mg} / \mathrm{g})$

$q_{o}$ is the monolayer adsorption capacity of the adsorbent (mg / $\mathrm{g}$ ),

b is the Langmuir adsorption constant $(\mathrm{L} / \mathrm{mg})$ and is related to the free energy of adsorption .

The essential characteristic of Langmuir Isotherm is expressed in terms of dimentionless constant separation factor or equilibrium parameter RL, is define as:

$\mathrm{RL}=1 /(1+\mathrm{bCo})$

Where $\mathrm{Co}_{\mathrm{o}}$ is the initial adsorbate concentration $(\mathrm{mg} / \mathrm{g})$ and $\mathrm{b}$ is the Langmuir constant (L/mg) (kimet et al, 2014). In the context, Lower $\mathrm{R}_{\mathrm{L}}$ value reflect the adsorption is more favorable. In deeper explanation, RL value indicate the adsorption nature is 
either unfavorable $\left(R_{L}>1\right)$, Linear $\left(R_{L}=1\right)$, favorable $\left(0<R_{L}>1\right)$, or irreversible $(R L=0)$ (Kimel et al, 2014).

\subsubsection{Freudnch Isotherms}

A freunlich Isotherm is a mathematical equilibrium between a fluid and a solid material. The freunlich expression is a mathematical equetion between an imperical expression representing the Isotherm variation of Liquid or gas on a solid material. The slope ranges between 0 and 1 is a measure of adsorption intensity or surface heterogeneity, becoming more heterogeneous as its value gets closer to zero. Whereas, a value below unity implies chemisorption process where $1 / \mathrm{n}$ above one is an indicative of cooperative adsorption. It's linearized and non-linear.

The linear form can be written as:

$\operatorname{Ln} q_{e}=\ln k_{f}+\left(\frac{1}{n}\right) \chi \ln C_{e}$

Where, $k_{f}$ and $\mathrm{n}$ (dimensionless constants) are the Freundlich adsorption isotherm constants, which indicates the capacity and intensity of the adsorption, respectively.

\subsubsection{Temkin Isotherm Model}

Temkin Isotherm assumes that the adsorption heat of all molecules decreases linearly with with the increase in the coverage on the surface of the adsorbent.

The general form of Temkin equation is giving below

$q_{e=\frac{R T}{b_{T}}+\ln A_{T} C_{e}}$

The linear form equation is written as

$q_{e}=\frac{R T}{b_{T}} \ln A_{T}+\frac{R T}{b_{T}} \ln C_{e}$ 
The curve is obtain by plotting $\mathrm{q}_{e}$ against $\ln \mathrm{C}_{\mathrm{e}}$, with $\mathrm{A}_{\mathrm{T}}$ as Temkin isotherm equilibrium binding constant $(\mathrm{L} / \mathrm{g}), \mathrm{b}_{\mathrm{T}}$ Temkin isotherm constant $\mathrm{R}$, is universal gas constant $(8.314 \mathrm{j} / \mathrm{mol} \mathrm{K})$ and $\mathrm{T}$, is temperature (J. Piccin et al, 2011)

\subsection{Groundnut Shell}

Groundnut botanically known as arachis hypogeal belongs to legumiminose family. A complete seed of groundnut is called the pod and the outer layer is called the shell. Brian George et al. investigate the groundnut shell fibers was found to be $38 \mathrm{~mm}$ and $0.2 \mathrm{~mm}$ diameter. Average tenacity of groundnut shell fiber is of $1.06 \mathrm{~g} / \mathrm{den}$. Also, average strain of the fibers was found to be 7.45percent and average modulus 25.3g/den (Khan et al, 2018)

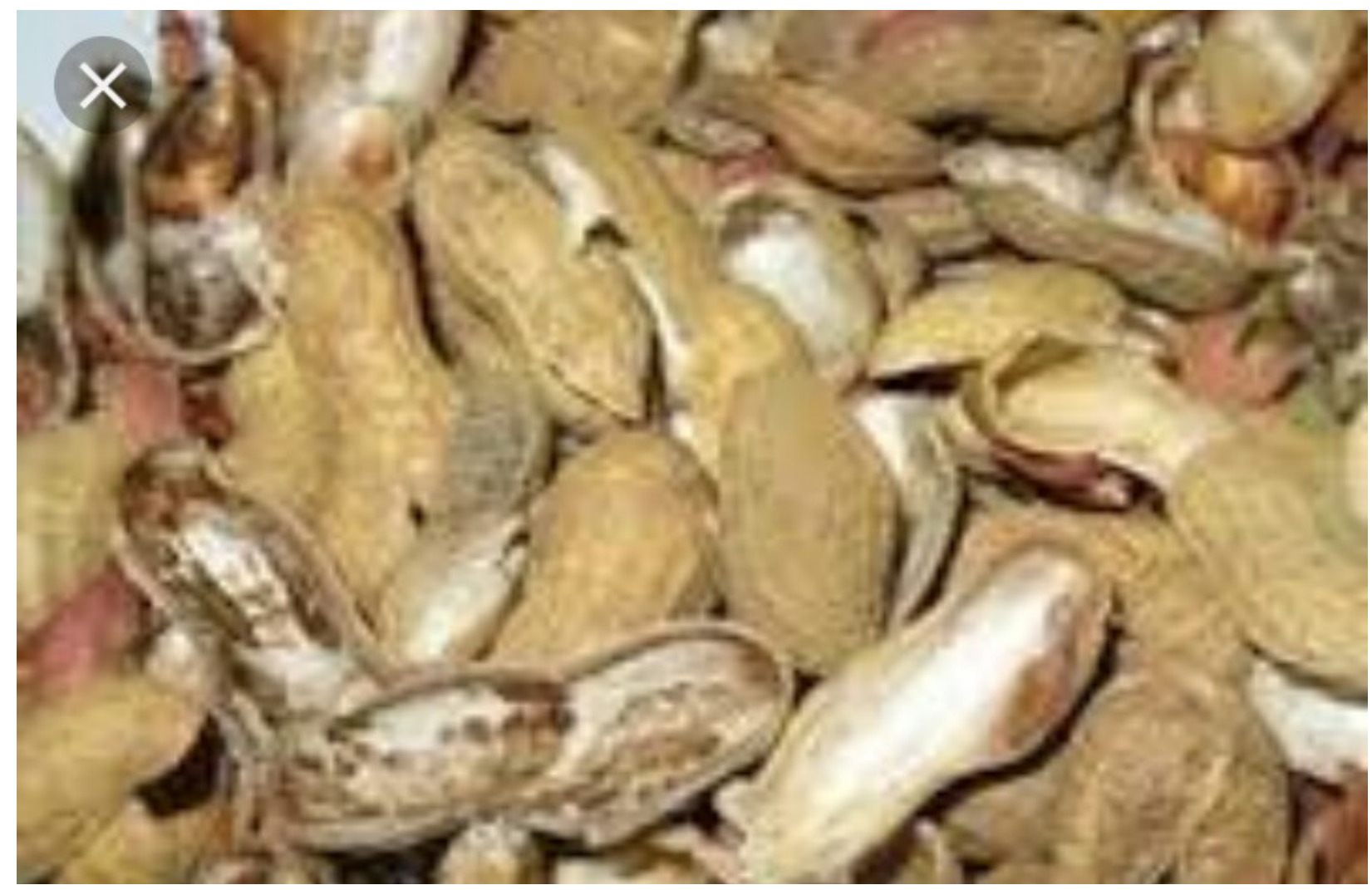

Fig 2.1: groundnut shell

\section{3 Surghum Husk}


Sorghum husk is an agricultural waste from milling of guinea corn (sorghum vulgare), guinea corn is an important food crop grown abundantly in northern part of niger and Benue Rivers in Nigeria. Attia et al. (2014) .

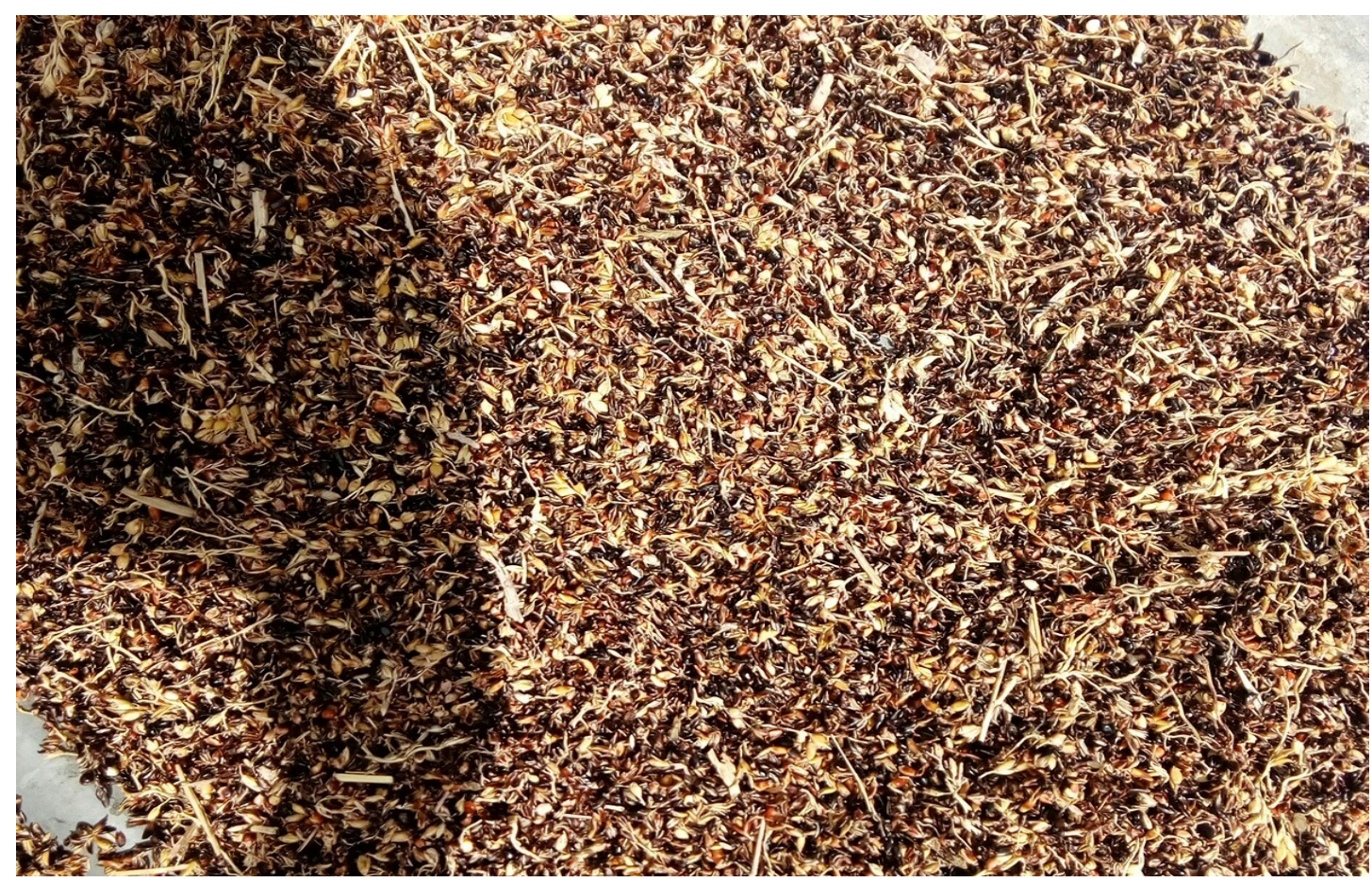

Fig 2.2: Sorghum husk

\subsection{MATERIAL AND METHODS}

\subsection{CHEMICAL}

Methylene blue dye chemical was used for the initial adsorption experiments. Other chemicals such as $\mathrm{NaOH}$ and $\mathrm{HCl}$ were used to keep the $\mathrm{pH}$ constant. The adsorbents used were groundnut shell and sorghum husk. 


\subsection{APPARATUS}

* Graduated cylinder

* UV spectrophotometer

* Beaker

* Orbital shaker

Separating funnel

* Sieve

* Distilled water

* PH meter

* balance

\subsection{PREPARATION OF THE ADSORBENT}

Adsorbents (groundnut shell and sorghum husk) were collected from Sabon kaura, Bauchi local government area, Bauchi state. The agricultural by product were washed and dried at low temperature $\left(<105^{\circ} \mathrm{C}\right)$ for 48 hours to remove moisture content. After the drying process, material were ground to fine powder and sieved through $600 \mu \mathrm{m}$ size. The adsorbents is then used for the research work.

\subsection{Procedure for Adsorption Isotherm Studies}


$50 \mathrm{ml}$ of methylene blue solution of concentrations $10 \mathrm{mg} / \mathrm{L}, 20 \mathrm{mg} / \mathrm{L}, 30 \mathrm{mg} / \mathrm{L}, 40 \mathrm{mg} / \mathrm{L}$ and $50 \mathrm{mg} / \mathrm{L}$ were prepared. $4.0 \mathrm{~g}$ of groundnut shell of the prepared sample was taken in to a conical flasks containing the solutions with a known initial concentration and the solution was maintained at a constant $\mathrm{PH}$ and stirred until equilibrium concentration is reached. The equilibrium concentration is recorded and used for the Isotherm study. The same procedure was used to carry out the same experiment using $3.6 \mathrm{~g}$ of sorghum husk and methylene blue dye solution.

\subsection{RESULTS AND DISCUSSION}

This section presents the results and discussions of the research.

The following data were used:

Volume of the solution used $=50 \mathrm{ml}$

Mass of sorghum husk used $=3.6 \mathrm{~g}$ 
Mass of groundnut shell used $=4.0 \mathrm{~g}$

Data obtained from adsorption of methylene blue on Surghum husk

\begin{tabular}{|r|r|r|r|r|r|}
\hline \multicolumn{1}{|l|}{$\mathrm{C}_{\mathrm{o}}(\mathrm{mg} / \mathrm{L})$} & \multicolumn{1}{|c|}{$\mathrm{C}_{\mathrm{e}}(\mathrm{mg} / \mathrm{L})$} & qe $(\mathrm{mg} / \mathrm{g})$ & $\mathrm{Ce} / \mathrm{qe}(\mathrm{g} / \mathrm{L})$ & $\ln \mathrm{qe}(\mathrm{mg} / \mathrm{L})$ & $\ln \mathrm{Ce}(\mathrm{mg} / \mathrm{L})$ \\
\hline 10 & 0.005 & 0.138889 & 0.036 & -1.97408 & -5.29832 \\
\hline 20 & 0.012 & 0.277778 & 0.0432 & -1.28093 & -4.42285 \\
\hline 30 & 0.021 & 0.416667 & 0.0504 & -0.87547 & -3.86323 \\
\hline 40 & 0.032 & 0.555556 & 0.0576 & -0.58779 & -3.44202 \\
\hline 50 & 0.051 & 0.694444 & 0.07344 & -0.36464 & -2.97593 \\
\hline
\end{tabular}

Data obtained from adsorption of methylene blue on Groundnut shell

\begin{tabular}{|r|r|r|r|r|}
\hline $\mathrm{Ce}(\mathrm{mg} / \mathrm{L})$ & Qe $(\mathrm{mg} / \mathrm{L})$ & $\mathrm{Ce} / \mathrm{Qe}(\mathrm{g} / \mathrm{L})$ & $\ln \mathrm{Ce}(\mathrm{mg} / \mathrm{L})$ & \multicolumn{1}{l}{$\ln \mathrm{Qe}(\mathrm{mg} / \mathrm{L})$} \\
\hline 0.011 & 0.138736 & 0.079287 & -4.50986 & -1.97518 \\
\hline 0.032 & 0.277333 & 0.115385 & -3.44202 & -1.28254 \\
\hline 0.055 & 0.415903 & 0.132242 & -2.90042 & -0.8773 \\
\hline 0.076 & 0.5545 & 0.13706 & -2.57702 & -0.58969 \\
\hline 0.121 & 0.692764 & 0.174663 & -2.11196 & -0.36707 \\
\hline
\end{tabular}

\section{Methylene Blue Adsorption on Sorghum Husk}

The Langmuir, Freundlich and Temkin Isotherm study for Methylene Adsorption on Sorghum husk was carried out. The Langmuir, Freunlich and Temkin plot were given in figure $4.1,4.2$ and 4.3 respectively.

The value of $\mathrm{q}_{\mathrm{e}}$ is calculated using equation (2.1) and the values needed for the calculation of Isotherms were recorded in Table above 


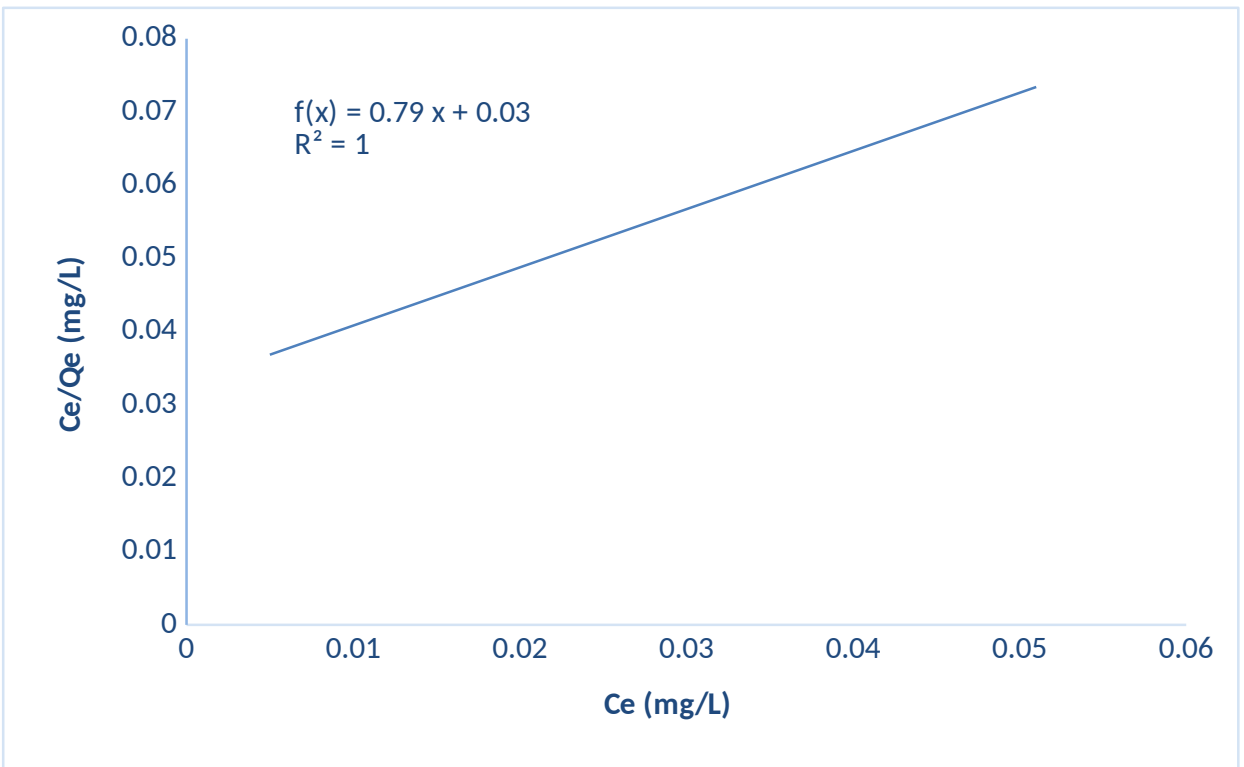

Fig 4.1: Langmuir Isotherm plot of MB on SH

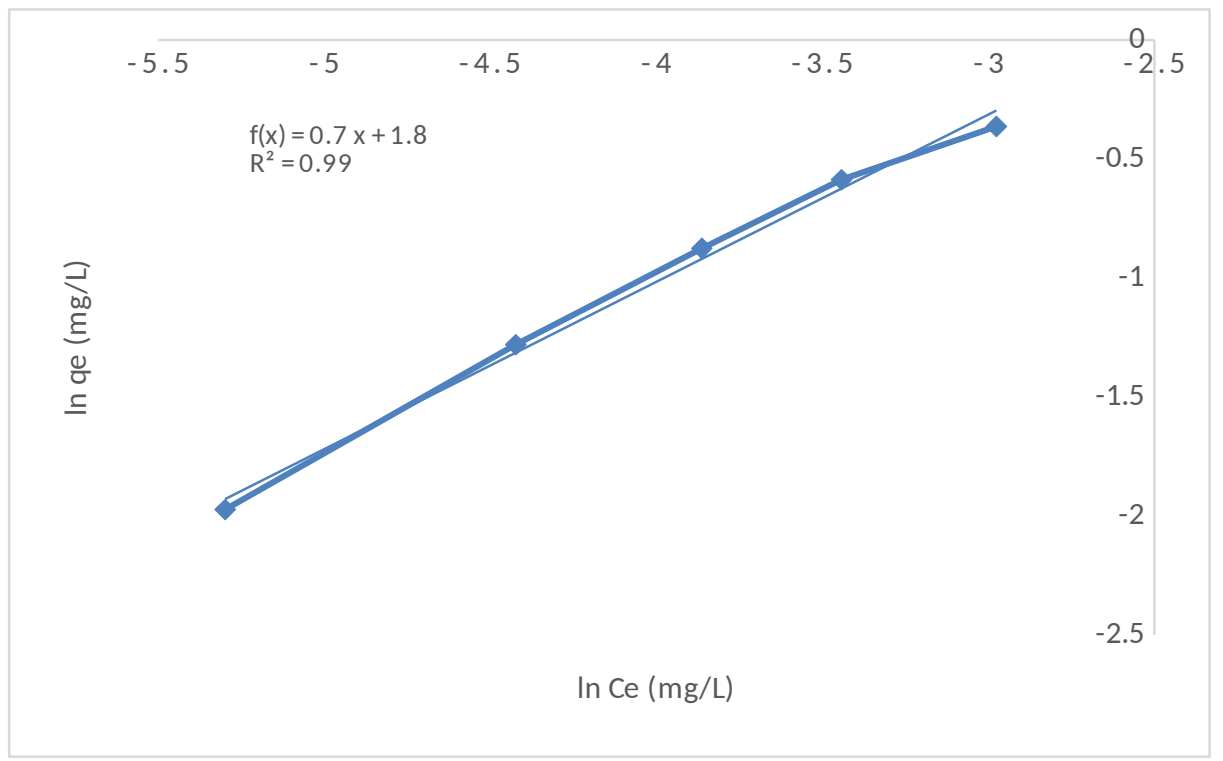

Fig 4.2: freundlich Isotherm of MB on SH 


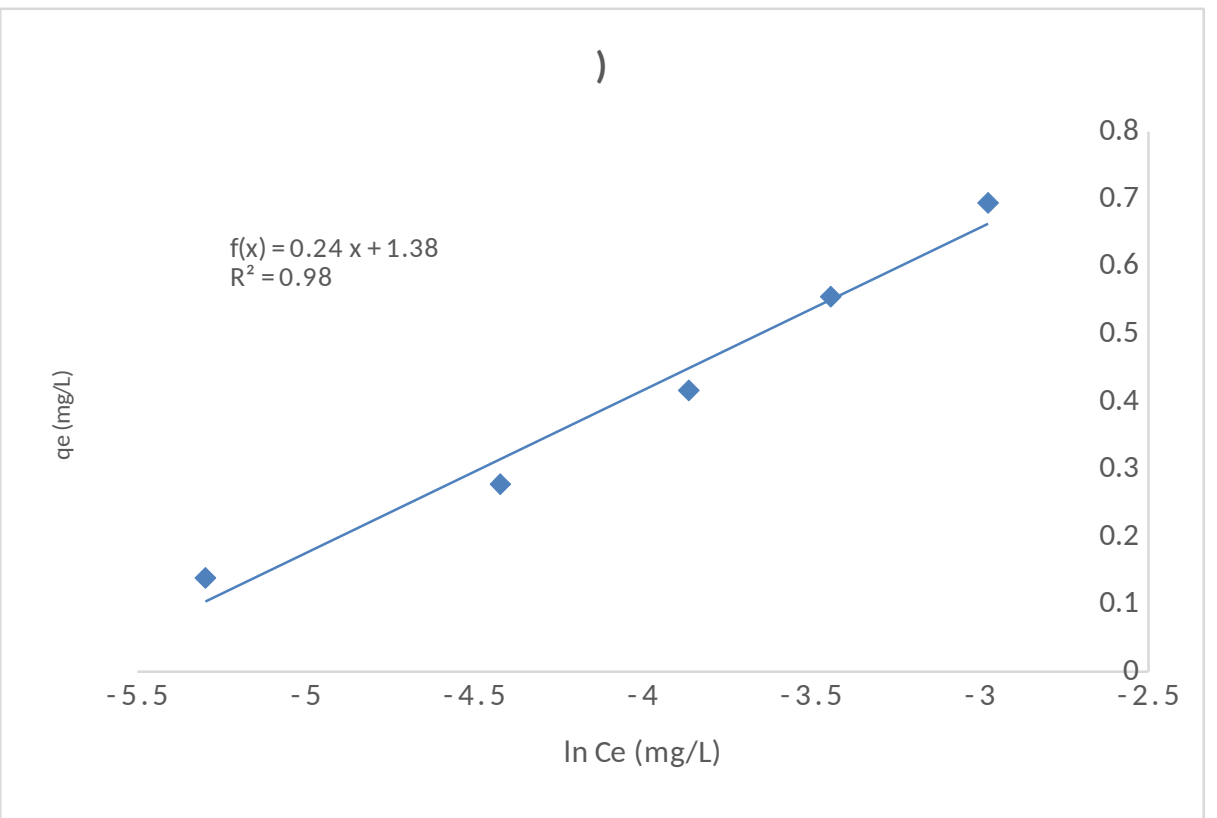

Fig 4.3: Temkin Isotherm of MB on SH

From the Langmuir, Freunlich and Temkin isotherm plot of methylene blue removal on sorghum husk, $R^{2}$ values of Langmuir constant was 0.99700 which is higher than $R^{2}$ value of freundlich and Temkin, this means that Langmuir data fitted well than freundlich (0.983) and Temkin (0.9758) data in the adsorption process and That shows that the process is a Monolayer adsorption process.

\subsection{Methylene blue adsorption on Groundnut Shell}

The Langmuir, freundlich and Temkin Isotherm for methylene blue adsorption on Groundnuts shell was carried out. The Langmuir, Freundlich and Temkin plots are given in fig $4.4,4.5$ and 4.6 respectively.

The value of $\mathrm{q}_{\mathrm{e}}$ is calculated using equation (2.1) and the Values needed for the calculation of Isotherms were recorded in Table A2. 


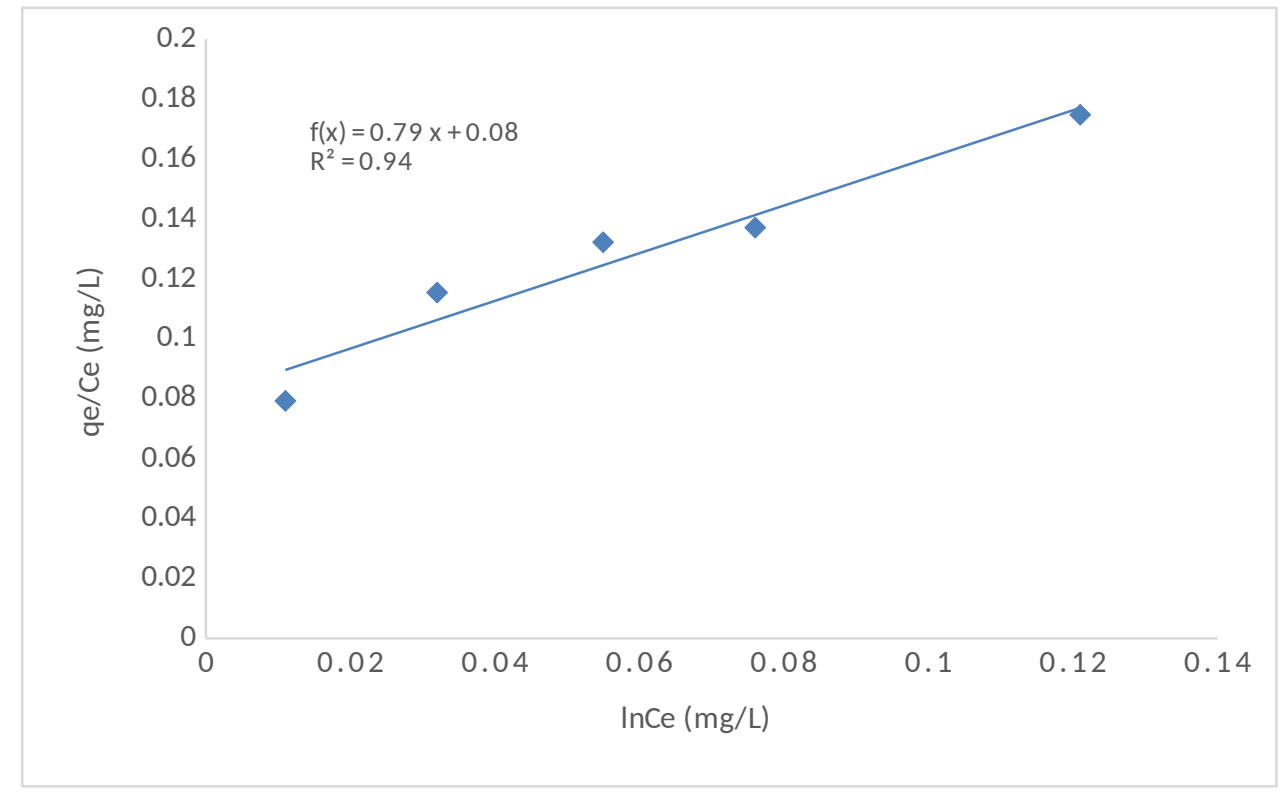

Fig 4.4: Langmuir Isotherm of MB on GS

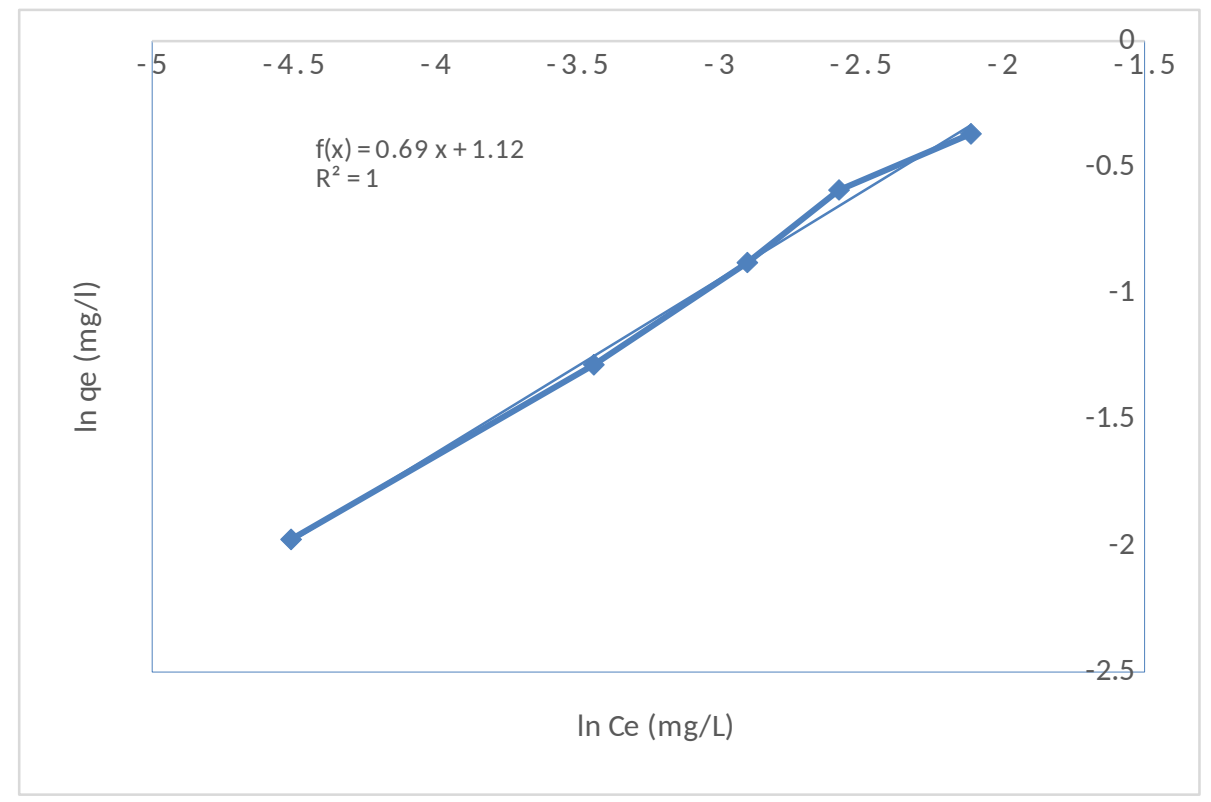

Fig 4.5: freunlich Isotherm plot of MB on GS 


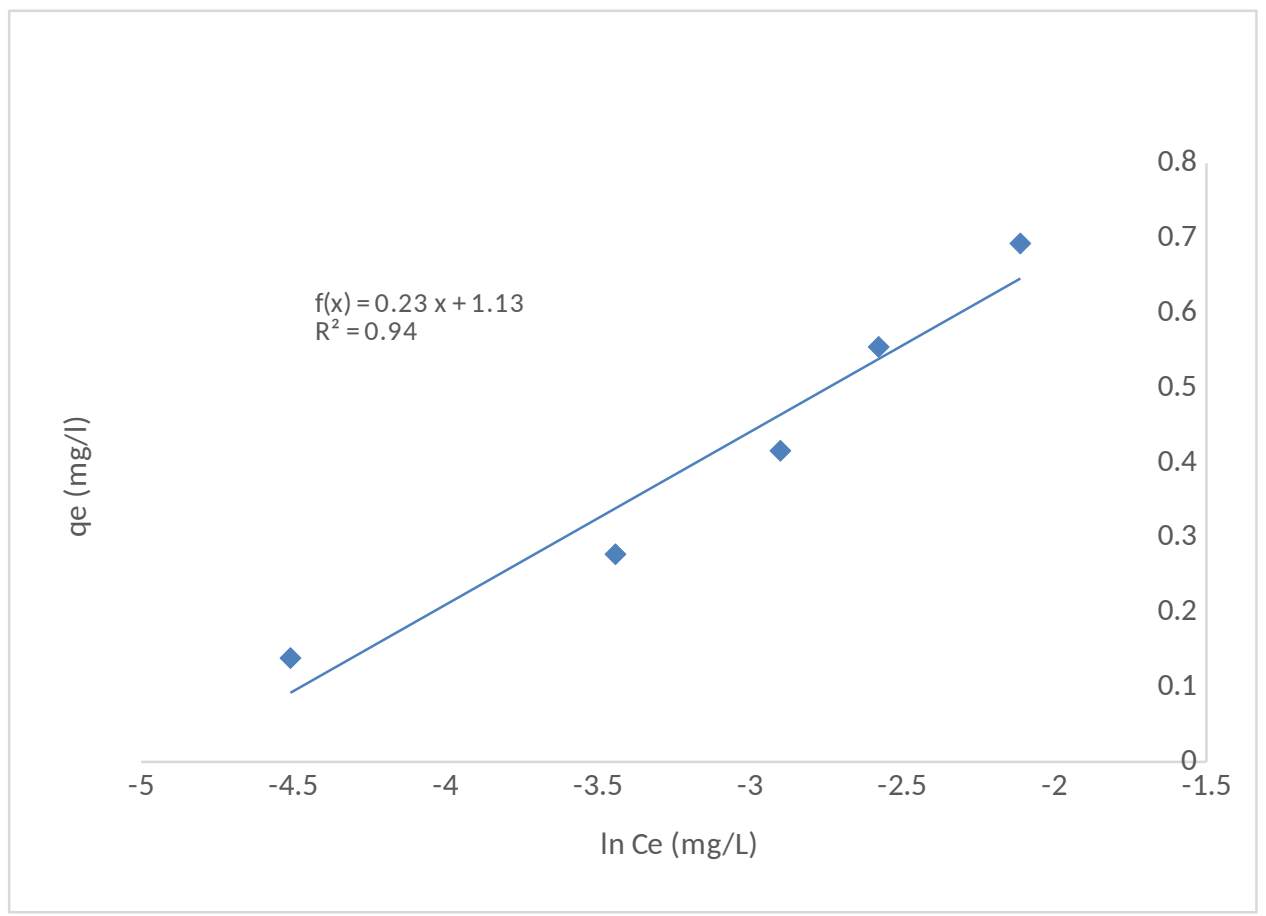

Fig 4.6: Temkin Isotherm plot of MB on GS

From the above Langmuir, Freunlich and Temkin isotherm plot of methylene blue removal on groundnut shell, $R^{2}$ value of freundlich constant is 0.960 which is higher than $R^{2}$ value of freundlich and Tebkin, this means that Langmuir data fitted well than Langmuir (0.9436) and Temkin (0.944) data in the adsorption process. That show that the Adsorption process is multilayer adsorption process.

4.3 
Table 4.1: Langmuir isotherm constant

\begin{tabular}{lll}
\hline & $\mathrm{MB}+\mathrm{GS}$ & $\mathrm{MB}+\mathrm{SH}$ \\
$\mathrm{Q}$ o $(\mathrm{mg} / \mathrm{g})$ & 1.2583 & 1.259 \\
$\mathrm{~b}(\mathrm{~L} / \mathrm{mg})$ & 9.9135 & 22.14 \\
$\mathrm{R}^{2}$ & 0.5436 & 0.9700 \\
\hline
\end{tabular}

For Langmuir isotherm; A plot of Ce/qe was plot agaist Ce which indicate a homogeneous adsorption distribution of Langmuir isotherm. The values of $b$ and Qo were obtained from the intercept and the slope of the graph.

Table 4.2: Freundlich isotherm constant

\begin{tabular}{llr}
\hline & $\mathrm{MB}+\mathrm{GS}$ & $\mathrm{MB}+\mathrm{SH}$ \\
$\mathrm{K}_{\mathrm{f}}(\mathrm{mg} / \mathrm{g})$ & 3.066 & 2.931 \\
$1 / \mathrm{n}$ & 0.6881 & 0.1734 \\
$\mathrm{n}$ & 1.4533 & 1.3624 \\
$\mathrm{R}^{2}$ & 0.9601 & 0.9758
\end{tabular}

From the freundlich constants (table 4.6), the values of $n$ are found to be greater than one $(n>1)$ indicating that the adsorption is a physical process. The values of $n$ ranges from 1-10 represent good adsorption process.

\section{Temkin Isotherm constant}




\begin{tabular}{|l|l|l|}
\hline & MB+SH & MB+GS \\
\hline$A_{T}$ & 1.0 & 1.0 \\
\hline$b_{T}$ & 10353.7 & 10793 \\
\hline$R^{2}$ & 0.976 & 0.944 \\
\hline
\end{tabular}

The Temkin binding energy $\left(b_{T}\right)$ are positive for all the experiment, indicating that the process is endothermic.

\section{SUMMARY}

The batch adsorption experiment on adsorption of methylene blue and Congo Red on groundnut shell and sorghum husk was carried out. The experiment data needed for the different isotherm were generated, adsorption isotherm such as Langmuir, Freundlich and Temkin models were used to fit the experiment data. Correlation coefficient was used to see how well the models best fits the data.

\section{CONCLUSIONS}

For the adsorption of methylene blue on sorghum husk, Langmuir Isotherm is more suitable to fit the experiment data because it has $R^{2}$ value of 0.9710 value than the other model, while for the adsorption of methylene blue on groundnut shell, Congo red on sorghum husk and Congo red on groundnut shell, Freundlich isotherm fitted well the experimental data due to high $R^{2}$ values of $0.960,0.983$ and 0.9720 respectively. The Temkin binding energy $\left(b_{T}\right)$ are positive for all the experiment, indicating that the process is endothermic. 


\section{REFRENCES}

Attia, A.A., Girgis, B.S., Khedr, S.A. (2013) Capacity of activated carbon derived from pistachio shells by H3PO4 in the removal of dyes and phenolics. J Chem Technol Biotechnol 78: 611-619.

Barka, N., Abdennouri M., Makhfouk M. E., (2017) Removal of Methylene Blue and Eriochrome Black T from aqueous solutions by biosorption on Scolymus hispanicus L.: Kinetics, equilibrium and thermodynamics. J Taiwan Inst Chem Eng 42: 320-326.

Chiou, M.S, Li, H.Y (2014) Adsorption behavior of reactive dye in aqueous solution on chemical cross- linked chitosan beads. Chemosphere 50: 10951105.

Dolphen, R., Sakkayawong N.T, Thiravetyan P.H, Nakbanpote, W,. (2016) Adsorption of Reactive Red 141 from wastewater onto modified chitin. J Haz Mater 145: 250-255.

Dursun, A.Y,. (2014) The effect of pH on the equilibrium of heavy metal bisorption by Aspergillus miger. Fresenius Environ Bull 12: 1315-1322.

Filipkowska, U.K., (2017) Adsorption and Desorption Efficiency of Black 8 and Black 5 onto Chitin and Chitosan.

J. S. Piccin, G. L. Dotto, L. A. A. Pinto., (2011) Adsorption Isotherm and thermochemical data Binding by Chitason. Brazilian journals of chemical engineers.

Khan, T.A., Singh, V.V., Kumar D., (2018) Removal of some basic dye from artificial textile waste water by adsorption on Akash Kinari coal. J Sci Ind Res 63: 355-364.

Khattri, S.D., (2016), Colour removal from dye wastewater using sugar cane dust as an adsorbent, Adsorp. Sci. Technol, 17, 269-282.

K. K. Upadhyay. (2019), Impact of dye on the Chemistry of water and its implication. Research trend. www.blobullotin.com

Kim, S.K., Rajapakse, N., (2015) Enzymatic roduction and biological activities of chitosan oligosaccharides (COS): A review. Carboh Pol 62: 357-368. 
Ponnusami, V., Srivastava S.N, Vikram S, (2016), Guava (Psidium guava) leaf powder: Novel adsorbent for removal of methylene blue from aqueous solutions, Journal of Hazardous Materials 152(1), 276-286. 